University of Nebraska - Lincoln

DigitalCommons@University of Nebraska - Lincoln

Nebraska Game and Parks Commission -- Staff

Research Publications

Nebraska Game and Parks Commission

2017

\title{
Implementing the 2012 North American Waterfowl Management Plan Revision: Populations, Habitat, and People
}

\author{
Dale D. Humburg \\ Ducks Unlimited, dhumburg@ducks.org \\ Michael G. Anderson \\ Institute for Wetland and Waterfowl Research \\ Michael G. Brasher \\ Ducks Unlimited \\ Michael F. Carter \\ Playa Lakes Joint Venture \\ John M. Eadie \\ University of California, Davis
}

See next page for additional authors

Follow this and additional works at: https://digitalcommons.unl.edu/nebgamestaff

Humburg, Dale D.; Anderson, Michael G.; Brasher, Michael G.; Carter, Michael F.; Eadie, John M.; Fulton, David C.; Johnson, Fred A.; Runge, Michael C.; and Vrtiska, Mark P., "Implementing the 2012 North American Waterfowl Management Plan Revision: Populations, Habitat, and People" (2017). Nebraska Game and Parks Commission -- Staff Research Publications. 88.

https://digitalcommons.unl.edu/nebgamestaff/88

This Article is brought to you for free and open access by the Nebraska Game and Parks Commission at DigitalCommons@University of Nebraska - Lincoln. It has been accepted for inclusion in Nebraska Game and Parks Commission -- Staff Research Publications by an authorized administrator of DigitalCommons@University of Nebraska - Lincoln. 


\section{Authors}

Dale D. Humburg, Michael G. Anderson, Michael G. Brasher, Michael F. Carter, John M. Eadie, David C. Fulton, Fred A. Johnson, Michael C. Runge, and Mark P. Vrtiska 


\title{
Implementing the 2012 North American Waterfowl Management Plan Revision: Populations, Habitat, and People
}

\author{
DALE D. HUMBURG, ${ }^{\mathbf{1}}$ Ducks Unlimited, One Waterfowl Way, Memphis, TN 38120, USA \\ MICHAEL G. ANDERSON, ${ }^{2}$ Institute for Wetland and Waterfowl Research, Ducks Unlimited Canada, Stonewall, Manitoba, RoC 2ZO, Canada \\ MICHAEL G. BRASHER, Ducks Unlimited, Gulf Coast Joint Venture, 700 Cajundome Blvd, Lafayette, LA 70506, USA \\ MICHAEL F. CARTER, Playa Lakes Joint Venture, 2575 Park Lane, Lafayette, CO 80027, USA \\ JOHN M. EADIE, Department of Wildlife, Fish \& Conservation Biology, University of California, Davis, One Shields Avenue 95616, USA \\ DAVID C. FULTON, U.S. Geological Survey, Minnesota Cooperative Fish \& Wildife Research Unit, University of Minnesota, Saint Paul, MN \\ 55108, USA \\ FRED A. JOHNSON, U.S. Geological Survey, Wetland and Aquatic Research Center, 7920 NW 71 Street, Gainesville, FL 32038, USA \\ MICHAEL C. RUNGE, U.S. Geological Survey, Patuxent Wildlife Research Center, Laurel, MD 20708, USA \\ MARK P. VRTISKA, Nebraska Game and Parks Commission, 2200 N. 33rd St., Lincoln, NE 68503, USA
}

\begin{abstract}
The North American Waterfowl Management Plan (NAWMP) has established a model for wildlife conservation planning over the last 3 decades. Management at a continental scale, leveraged funding, regional partnerships, and a strong science basis have been notable features. Periodic updates to the NAWMP occurred since implementation in 1986; however, a fundamental revision was accomplished in 2012 after extensive stakeholder engagement. An explicit fundamental goal for waterfowl conservation supporters was added in 2012, complementing existing goals for sustainable populations and sufficient habitat found in previous updates. We present a synopsis of progress toward implementation of the 2012 NAWMP and challenge the waterfowl management community to continue with meaningful steps toward achieving NAWMP goals. Adding goals and objectives for supporters increases potential relevance of NAWMP; however, it also presents a level of complexity that was not entirely anticipated. Additionally, the 2012 NAWMP recognized that traditional support from waterfowl hunters alone will not be sufficient to support waterfowl conservation in the future. Simultaneous consideration of multiple objectives, although implicit before, now is a specific focus for habitat and harvest management affecting hunters and other users of the waterfowl resource. The waterfowl management community is faced with revisiting objectives and management actions related to harvest regulations, landscape priorities, habitat conservation, and public engagement to garner broader support. These persistent management challenges are tangible and relevant candidates for greater integration. Ultimately, the structures and processes supporting waterfowl management also will need to be reconsidered. (c) 2017 The Wildlife Society.
\end{abstract}

KEY WORDS adaptive management, conservation planning, harvest regulations, human dimensions, NAWMP, tradeoff, waterfowl, wetlands.

Waterfowl conservation and management at a continental scale have evolved over the last century. The Convention for the Protection of Migratory Birds (1916) set the stage for international management of waterfowl (Anderson et al. 2018), funding has been assured through legislation (e.g., Migratory Bird Hunting and Conservation Stamp Act of 1934), and the Flyway Council System provided a framework

Received: 2 March 2017; Accepted: 26 September 2017

${ }^{1}$ E-mail: dhumburg@ducks.org

${ }^{2}$ Retired for cooperative management beginning in the early 1950s (Jahn and Kabat 1984). This historic commitment was complemented further as continental population and harvest surveys were developed, providing the scientific basis for waterfowl conservation during the last 60 years (Blohm 2006, Anderson et al. 2018).

These foundations were essential prerequisites for the North American Waterfowl Management Plan (NAWMP). Although declining waterfowl populations and eroding habitat were the proximate impetus for the NAWMP during the early 1980s, long-term coordinated management was the primary intent. Periodic updates, at roughly 5 -year intervals, have ensured that the NAWMP continues to evolve and 
remain a preeminent model for long-term conservation planning at a continental scale, based on quantitative objectives, and a strong scientific grounding.

The initial NAWMP, subtitled "A Strategy for Cooperation," laid out overall goals based on duck population levels during the 1970s, which were assumed to be sufficient for hunting and other diverse public interests (U.S. Department of the Interior and Environment Canada 1986). Expanded partnerships, conservation delivery through Joint Ventures (JV), sustained funding through the North American Wetlands Conservation Act (NAWCA), and a strong commitment to biological foundations of waterfowl management characterized progress during the first 2 decades of the NAWMP.

Changes in perspectives emerged as a Joint Task Group (Anderson et al. 2007) challenged the waterfowl management community to align objectives for waterfowl harvest and habitat management (Runge et al. 2006). Concurrently, increased focus on social science and human dimensions led to a survey of waterfowl hunters in the United States (National Flyway Council and Wildlife Management Institute 2006) and these topics were front-and-center in discussions at the Future of Waterfowl Management Workshop (Case and Sanders 2008). The workshop also added momentum for a fundamental revision of NAWMP goals and objectives. "People Conserving Waterfowl and Wetlands," the subtitle of the 2012 NAWMP, captured a fundamental and expanded vision for NAWMP that now includes an explicit focus on waterfowl hunters and other waterfowl conservationists (U.S. Department of the Interior et al. 2012a). Considering the existing challenges of managing diverse landscapes at a continental scale and across multiple agencies, adding goals and objectives for human dimensions increased complexity to a greater degree than authors of NAWMP may have anticipated. The explicit focus on supporters, however, provides more complete and relevant context for waterfowl management and represents further maturity in conservation planning.

Progress toward 2012 NAWMP goals was reported during a special session at the seventh North American Duck Symposium. Our purpose is to present a synopsis of that session and challenge the waterfowl management community to continue with meaningful steps toward NAWMP goals.

\section{IMPLEMENTING THE 2012 NAWMP}

Goals, recommendations, and key actions outlined in the NAWMP Action Plan (U.S. Department of the Interior et al. 2012b) provided the framework for implementation of the 2012 NAWMP. Individuals directly involved with waterfowl research, management, planning, and stakeholder engagement summarize progress toward NAWMP goals in the sections to follow. These represent collaborations among many NAWMP partners and our experience gained over the 30 years of the NAWMP. We emphasize the need to clarify objectives, focus on a few key integration challenges, consider possible amendments to the institutions and processes of waterfowl management, and commit to adaptive management.

\section{TRANSLATING VALUES INTO OBJECTIVES}

Among 7 recommendations in the 2012 NAWMP, was "Develop, revise, or reaffirm NAWMP objectives so that all facets of North American waterfowl management share a common benchmark" (U.S. Department of the Interior et al. 2012a:xii). Subsequently, NAWMP's objectives were revised in 2014 for the first time since 1986 (NAWMP Committee 2014; Table 1). The revised objectives are assumed to approximate the values of stakeholders wherein numbers of birds are sufficient to satisfy hunting and non-hunting uses, and habitat distribution and abundance are adequate to provide for birds and users. These assumptions, however, have not been investigated by rigorous social science methods and undoubtedly will be affected by ecological and social change.

Ultimately, like all natural resource management issues, waterfowl management decisions involve positive and normative questions (Fenichel et al. 2013a). Positive questions are addressed through the scientific collection of data on waterfowl populations, habitat, ecosystem functions, and human dimensions (e.g., hunter participation rates, motivations, economic expenditures, preferences). These are the objective bases and facts that allow decision makers to understand functions and predict outcomes of waterfowl management.

Conversely, normative questions involve subjective judgments about the waterfowl management outcomes we should try to achieve. Conservation planners have recognized for $\geq 50$ years, although often only implicitly, that normative choices are key aspects of every management endeavor (Davidoff and Reiner 1962, Vaske et al. 2001, Fulton et al. 2002). At a fundamental level, these normative choices are linked to human psychological, social, and cultural values (Fulton et al. 1996, Manfredo 2008, Manfredo et al. 2016). Values are theorized in the social sciences to be relatively stable constructs that reflect human desires for behavior and outcomes on the individual level and also expressed at higher levels of social organization (Rokeach 1973; Schwartz 1992, 2006). Objectives and management actions ultimately fail or lead to systemic conflicts when human values underlying the normative aspects of planning and decision making are not explicitly clarified (Wondolleck and Yaffee 2000). Thus, substantive involvement of stakeholders in decision processes provides one mechanism for identifying and including human values into management decisions.

Choices about whose values and which normative frameworks to apply in decision making are centuries-old challenges (Freeman 1992). Although exploration of stakeholder values and desires is key to successful planning, converting general values to meaningful quantitative objectives and measurable outcomes for waterfowl management can be extremely challenging. This is problematic because quantitative decision analysis and planning approaches are vital to waterfowl management under the NAWMP. In contrast, stakeholder involvement provides a qualitative discussion and assessment of values but often is 
Table 1. Fundamental goals and revised objectives from the 2012 North American Waterfowl Management Plan and the 2014 addendum to the 2012 North American Waterfowl Management Plan.

\begin{tabular}{|c|c|c|c|}
\hline & \multicolumn{3}{|c|}{2012 North American Waterfowl Management Plan } \\
\hline & Populations & Habitat & Supporters \\
\hline $\begin{array}{l}\text { Fundamental } \\
\text { goals }\end{array}$ & $\begin{array}{l}\text { Abundant and resilient waterfowl } \\
\text { populations to support hunting and other } \\
\text { uses without imperiling habitat. }\end{array}$ & $\begin{array}{l}\text { Wetlands and related habitats sufficient to } \\
\text { sustain waterfowl populations at desired } \\
\text { levels, while providing places to recreate } \\
\text { and ecological services that benefit society. }\end{array}$ & $\begin{array}{l}\text { Growing numbers of waterfowl hunters, } \\
\text { other conservationists, and citizens } \\
\text { who enjoy and actively support } \\
\text { waterfowl and wetlands conservation. }\end{array}$ \\
\hline $\begin{array}{l}\text { Revised } \\
\text { objectives }\end{array}$ & $\begin{array}{l}\text { Maintain long-term average populations of } \\
\text { breeding ducks (1955 to } 2014 \text { in the } \\
\text { Traditional Survey Area [TSA] and } 1990 \\
\text { to } 2014 \text { in the Eastern Survey Area } \\
\text { [ESA]) and periodically, } \geq 40 \text { million } \\
\text { breeding ducks and } \geq 2.7 \text { million breeding } \\
\text { ducks in the TSA and ESA, respectively. }\end{array}$ & $\begin{array}{l}\text { Conserve a habitat system with the capacity } \\
\text { to maintain long-term average waterfowl } \\
\text { population levels, to periodically support } \\
\text { abundant populations, and to consistently } \\
\text { support resource users at objective levels. }\end{array}$ & $\begin{array}{l}\text { Increase waterfowl conservation support } \\
\text { among various constituencies to at } \\
\text { least the levels experienced during the } \\
\text { last } 2 \text { decades. }\end{array}$ \\
\hline
\end{tabular}

insufficient to facilitate quantified management objectives. Psychometric approaches that focus on measuring human values and wildlife value orientations help to understand preferences for broad wildlife management goals (Teel and Manfredo 2009), but they do not necessarily predict preferences in specific decision contexts.

Beginning in the early 1970s, social science researchers suggested that understanding the motivations and experiences that hunters and anglers desired was key to defining what should be produced by agencies through activities like waterfowl management (Driver 1985). The development of multiple satisfactions (Hendee 1974) and experience-based (Driver and Knopf 1976) approaches for fisheries and wildlife management led to the development of experienced-based and benefits-based planning frameworks. These frameworks explicitly identify outcomes or benefits desired by stakeholders that reflect values-based or normative preferences (Driver 1996, 2008; Manfredo 2002). Although widely adopted for general outdoor recreation management (Driver 2008), such approaches generally have not been applied in fisheries and wildlife management because understanding motivations alone does not afford tight prediction of satisfaction for anglers or hunters (Arlinghaus 2006).

Recent efforts focusing on fisheries and wildlife management integrate social science and biological models to balance multiple outcomes related to population levels, habitat conditions, satisfaction with recreational experience, and human well-being (Johnston et al. 2010, Fenichel et al.2013b). Fenichel et al. (2013a) argue that a bioeconomics framework (Clark 2005) integrates positive science and normative objectives in a rigorous and quantitative way. The approach explicitly addresses a science-based description of the ecological and human dimensions components of the system, policy or regulatory mechanisms, and normative or valuesbased criteria that rank the desirability of management outcomes (Fenichel et al. 2013b). The approach is well-suited to dynamic optimization approaches frequently used in structured decision making (Williams et al. 2001, 2007).

The values considered in this approach are the individual preferences for personal outcomes that are derived from the values that influence choices in specific contexts (McFadden 2001). These context-dependent preferences change over time much more rapidly than the values defined by social psychological theory. The weighted aggregation of individual preferences yields social preferences that are an emergent property of the social-ecological system. Various approaches are used to weight the individual preferences leading to a collective preference (Fenichel et al. 2013a). This captures the normative considerations that need to be considered and explicitly adjudicated across individuals and groups of individuals. Decisions on how to normatively weight preferences will always be challenging, but a rigorous, quantitative approach for describing individual preferences that can be compared across individuals and groups is a helpful starting point.

Discrete choice modeling (DCM) provides a technique for better understanding recreationists' choices and the preferences they reflect (Louviere et al. 2000, McFadden 2001, Train 2003, Arlinghaus 2006). Fenichel et al. (2013b) describe the broad application and usefulness of DCM for understanding fishing or hunting choices, tradeoffs among alternatives, and for explaining and forecasting participation. As such, DCM provides a flexible tool for better understanding how hunters' preferences for where and how to hunt can be integrated with NAWMP objectives for waterfowl populations and habitat.

The DCM approach assumes that individuals seek to maximize their utility through choices that combine preferences and constraints. Utility is an individual's perceived usefulness or benefit of something to themselves, such as the number of ducks they harvest (Louviere et al. 2000). A utility function can then be defined that describes the pattern and importance of preferences for different attributes of waterfowl hunting. These attributes might include the numbers of ducks harvested, other hunters present, ducks present, distance traveled, difficulty of access, and other features of the hunt. The utility functions define equivalent levels of utility or indifference for different attributes. For example, how many ducks need to be harvested to compensate for traveling an additional hour, or how many fewer people need to be encountered to compensate for more difficult access?

Utility functions capture the values of attributes in arbitrary measures of utility. To address the normative concerns 
inherent in waterfowl management decisions, individuals' utilities must be normalized and aggregated into a social welfare function. This society-level score captures social well-being or what is good at the society level. Meaningful comparisons can be made for an individual or across individuals by normalizing the utility measures across attributes. This first step in normalizing a utility function then allows for more explicit consideration of normative weighting and consideration of management alternatives and objectives.

In addition to providing a framework for normative decision making and integrating values into objectives, the heterogeneity underlying choices can be modeled through latent class approaches (i.e., typology) or simulation using individual-level data. By understanding the heterogeneity of choices, decision makers can begin to understand how different groups might be affected by regulations and policies and how the welfare of those groups might differ from one another under different management scenarios.

Consideration of multi-objective decision making and multiple utility functions creates an even more complex decision environment (Fenichel et al. 2013b). As a step to addressing the normative consideration of decision making, a Human Dimensions Working Group (HDWG) is implementing DCM across the 4 waterfowl flyways (Fig. 1) in the United States and Canada to better understand preferences of waterfowl hunters and birders for different attributes of their hunting or viewing experiences. By better understanding the utility of selected attributes, we will develop the utility and social welfare functions necessary to inform objectives for waterfowl populations, habitat, and regulations.

\section{MANAGING FOR MULTIPLE OBJECTIVES}

Traditionally, North American waterfowl harvest management and habitat conservation programs operated largely independently of each other (Runge et al. 2006). Harvest regulations have been constructed primarily to allow take of

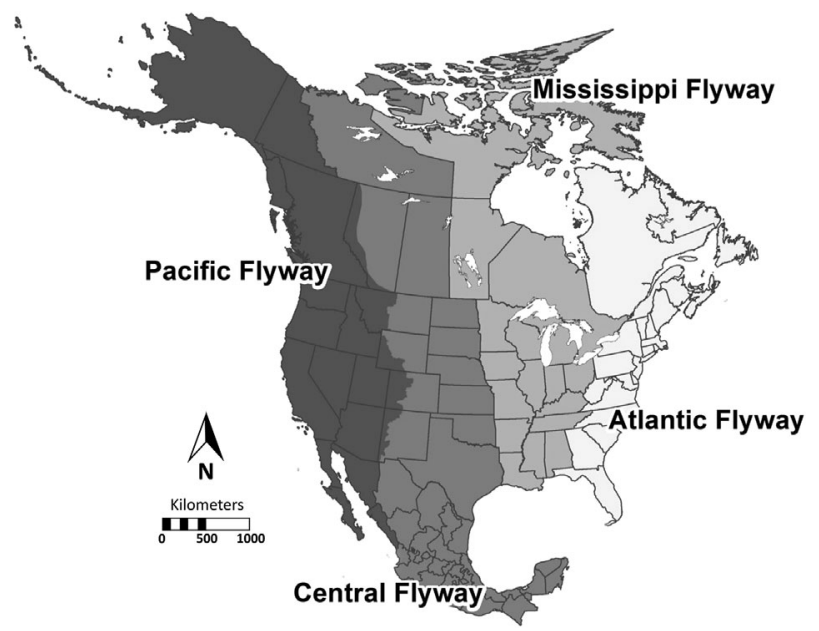

Figure 1. Administrative waterfowl flyways in North America (https:// www.fws.gov/birds/management/flyways.php). waterfowl populations while sustaining stocks of birds. Habitat conservation has been undertaken mainly to affect the carrying capacity of the landscape and to influence waterfowl population vital rates (e.g., female survival, reproductive success) that contribute to population growth. Providing harvest opportunity has been, at best, a secondary consideration for habitat projects on migration and wintering areas. Mostly, however, hunters and other recreational users were assumed to benefit simply as the result of well-managed and abundant bird populations and habitats.

Logically, objectives for waterfowl populations, waterfowl habitat, and engagement of waterfowl supporters are inseparably linked, as became apparent in consultations leading up to the 2012 NAWMP (Fig. 2). Thus, managers were challenged to simultaneously consider goals for sustaining populations, supporting human users, and conserving habitats for multiple values (U.S. Department of the Interior et al. 2012a,b). This was perceived as a means to enhance the effectiveness and efficiency of NAWMP delivery and strengthen the relevance of waterfowl conservation to a broad group of stakeholders. Planners hoped that increased relevance would result from purposeful integration of stakeholder considerations into objective setting and implementation. Coupled with a commitment to being adaptable in response to changing ecological and social landscapes, these improvements, in turn, were seen as vital to the long-term sustainability of waterfowl conservation as North Americans enjoyed it in the second half of the twentieth century.

The difficult, but better-circumscribed goal of the Joint Task Group (Anderson et al. 2007) was to seek a way to ensure that mid-continent mallard (Anas platyrhynchos) harvest strategies and related habitat conservation actions were pursued in a coherent, non-conflicting manner. The 2012 NAWMP set out a much more ambitious agenda, that of pursuing North American waterfowl management in a broadly integrated framework that would accommodate simultaneous pursuit of multiple objectives related to harvest

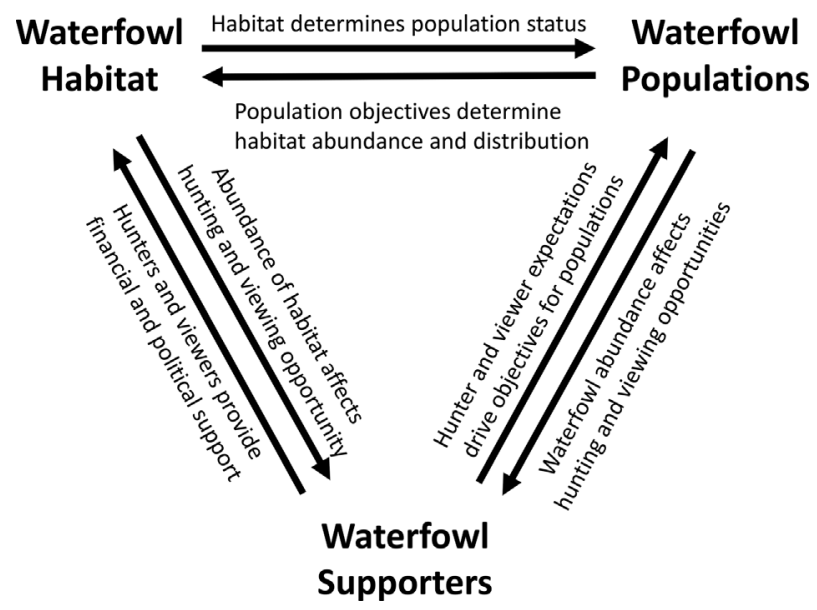

Figure 2. Fundamental goals and objectives for waterfowl management are inextricably linked (U.S. Department of the Interior et al. 2012a). 
regulation, population size, habitat conservation, users, and supporters. This would involve managing adaptively within a framework comprised of multiple decision processes and actors operating at multiple spatial and temporal scales. We use adaptive management generically to include strategic habitat conservation (U.S. Fish and Wildlife Service [USFWS] 2006), structured decision processes, and other formal approaches for recurrent decisions (Gregory and Keeney 2002, Williams et al. 2007, Williams 2011).

Such a multi-objective approach, inherently involves tradeoffs among actions designed to achieve individual objectives, values that likely differ among stakeholders, and the legal responsibility of agencies for trust resources. All of the typical uncertainties involved in resource management decisions (e.g., structural uncertainty, environmental variation, observation error, partial controllability; Walters 1986, Hilborn 1987, Williams et al. 2001, Williams 2011) remain and are augmented by uncertainties about how actions for each objective may affect attainment of other objectives.

The transition from coherence defined narrowly, to integration defined broadly, implied more complex decisions and linkages at multiple spatial and temporal scales, involving multiple and sometimes diffuse decision authorities and processes. These complexities were elaborated little in NAWMP, and progress with this broader agenda has been slow for at least 2 reasons: concern that the social issues were too diverse, complex, or poorly understood to allow confident incorporation in decision analyses; and skepticism that much could be gained in efficiency or program effectiveness via integration.

Admittedly, doing this is complex, but multi-criteria decision analysis (Herath and Prato 2006) provides a set of useful tools for understanding and navigating such tradeoffs. There is a 4-fold challenge in making decisions that would affect this array of waterfowl objectives. First, all of the separate fundamental objectives need to be clearly articulated. Second, the linkages among objectives, as influenced by various decision contexts, need to be understood. It might be useful to think about which sets of objectives need to be actively integrated because certain decisions directly affect them all. Other sets of objectives might only need to be passively integrated when achievement of one objective is conditional on achievement of another, but they do not directly compete. Third, models need to be developed (and tested over time) that predict the performance of the management alternatives against the multiple objectives, recognizing the linkages among the decision contexts and objectives. Fourth, for those objectives for which there are tradeoffs, a process of weighting the objectives is needed. Recognizing 2 things may help us make progress: 1 ) not all of the decisions and objectives are linked, so several smaller models, rather than a comprehensive, fully integrated model, should suffice and 2) the central role of predictive modeling provides a way to articulate linkages by predicting the effects of decisions on waterfowl, their habitats, and the users who enjoy them.

Some progress has been made by the NAWMP community in specifying the scales and nature of decision contexts important for waterfowl conservation, but much work is still needed on this topic. A few initial observations are that 1) waterfowl management involves many decision contexts that vary in scale (i.e., spatial, temporal, political, institutional); 2) many decision authorities exist, some quite formal and welldefined (e.g., the USFWS Service Regulations Committee), whereas others are diffuse (e.g., partnerships found in JV management boards); 3) system control varies greatly among decisions and in some cases appears tenuous; 4) related monitoring and assessment functions to support adaptation over time are disparate and may be uncoordinated among decision classes; 5) no single entity has responsibility for most interrelated decisions; and 6) institutional history presently may constrain participation in some decisions by all stakeholder organizations.

A waterfowl management system that is inclusive of the multiple goals and objectives of the 2012 NAWMP would be 1) adequately integrated but as simple as possible; 2) coordinated from continental scales to local management areas; 3) effective, efficient, and relevant to stakeholders, and thus widely embraced; and 4) responsive to changes and emerging needs at all scales at which we operate. Assuming we can specify fundamental objectives, and identify and model those linked decisions that are most vital, the next key challenge will be developing the monitoring and assessment feedback loops needed to track progress and reduce uncertainty about system dynamics.

\section{INTEGRATING WATERFOWL MANAGEMENT}

Simultaneously considering multiple goals and objectives presents a fundamentally greater challenge technically and socially than addressing single outcomes. Despite the countless decisions at various scales involved in waterfowl management, most are straightforward, involve specific management actions, and result in relatively predictable outcomes (Keeney 2004). A few persistent management challenges involve integrated management objectives and numerous, often uncertain results, which need to be explored in greater depth if the goals of the 2012 NAWMP are to be effectively and efficiently advanced. Among these are annual decisions about harvest management, allocation of limited budget resources among landscapes important to waterfowl and users, and decisions about how to deliver conservation within landscapes with widely variable social and ecological challenges.

\section{Harvest Management}

Fundamentally, waterfowl harvest regulations have been designed to ensure that species or populations are not overharvested (Williams and Johnson 1995). The annual process of recommending and promulgating regulations often has been contentious, however, balancing objectives for waterfowl populations with a desire to accommodate hunters. A turning point in setting waterfowl harvest regulations came in 1995 with the implementation of Adaptive Harvest Management (AHM) in the United States (Johnson et al. 2015), which provided needed 
structure in the annual decision-making process for setting regulations.

Adaptive harvest management has continued and now has entered the double-loop learning phase wherein reexamination of objectives, operating premises and protocols, and ecological or social processes occur (Pahl-Wostl 2009, Johnson et al. 2015; Fig. 3). The renewed focus on objectives stems from recent awareness about a declining hunter base and possible changes in hunter satisfaction that may be related in part to the effects of harvest regulations (Johnson and Case 2000, Vrtiska et al. 2013). Historically, hunter participation declined when duck populations were low and harvest regulations were more restrictive and vice versa (Vrtiska et al. 2013). Recent trends of declining waterfowl hunter numbers despite more liberal regulations and higher duck populations indicate this pattern may no longer be the case (Vrtiska et al. 2013), and perhaps other attributes of a hunting experience drive hunter engagement.

Developing explicit harvest management objectives was key to initial development of AHM and will again be important as objectives are revisited. Agreeing on unambiguous objectives has been difficult in the past and likely will not be any easier in the future (Johnson et al. 2015). Increased difficulty may result from changes in objectives (e.g., hunter participation), recognition that there are multiple objectives, and the inextricable linkages among objectives and management actions.

The original management objective codified in AHM (i.e., maximize long-term cumulative harvest while maintaining mallard population size above the NAWMP goal; Johnson et al. 1997) implicitly assumed that maximizing harvest would provide ample hunting opportunity and thus, hunter satisfaction and participation. Managers now are faced with considering how regulations affect multiple objectives for ducks and hunters. Actions that might affect one objective (e.g., populations) must be considered in the context of other competing objectives (e.g., increasing the number of waterfowl hunters).

Concern over a declining constituent base has led to strategies for recruitment, retention, and reactivation, key elements in addressing hunter engagement and identifying potential barriers to participation (A. H. Raedeke, Missouri Department of Conservation, unpublished report; Council to Advance Hunting and Shooting Sports 2016). One, among a number of perceived barriers to participation that are under managers' control, is regulation complexity (e.g., species-specific bag limits, zones, and split seasons). In general and simplistic terms, 2 groups of hunters can be characterized as those who understand complex regulations, have negotiated potential barriers, and favor maximum hunting and harvest opportunity and inexperienced hunters who favor simple regulations so as to ensure understanding and compliance. Although surveys generally indicate that hunters tend to favor more opportunity (i.e., season length, bag limits) over simpler regulations (Ringelman 1997, National Flyway Council and Wildlife Management Institute 2006), how current or potential hunters perceive complexity is poorly understood. Most surveys generally do not sample potential, new, or lapsed waterfowl hunters and thus, may not have detected some of the potential tradeoffs associated with certain regulations.

Tradeoffs occur between regulations developed to maximize hunting and harvest opportunity versus regulations designed to conserve certain duck stocks. For example,

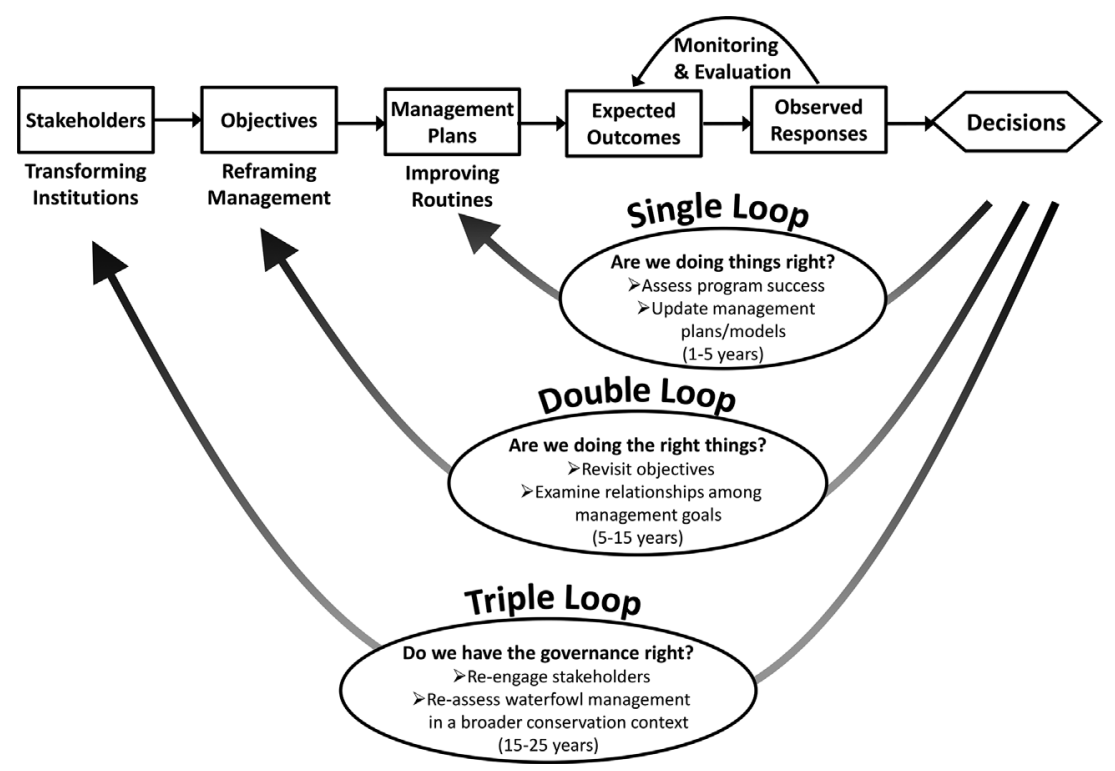

Figure 3. Cycles of learning and adaptive management involve the articulation of clear objectives by stakeholders, which lead to management plans consistent with those objectives. Monitoring and evaluation allows managers to measure and compare outcomes with original expectations, test the performance of planning models and assumptions, and to revise management in light of new information. Periodically, objectives may need to be reframed given new constraints and opportunities. At more infrequent intervals, the institutions and structures that support these decision-making processes may need to be revisited and transformed in the context of changing stakeholder and societal needs. Adapted from Pahl-Wostl (2009), Williams et al. (2007), and U.S. Department of the Interior et al. $(2012 b)$. 
relatively simple regulations might result by managing for the lowest harvest potential among duck stocks (e.g., short seasons or low daily bag limits), but this would result in lost hunting opportunity for abundant species or populations. Conversely, simple regulations could result from moderate regulations overall (e.g., 4-duck daily bag limit with no species-specific restrictions), but this might increase the risk of adversely affecting certain duck stocks.

Indeed, proliferation in the number of species-specific regulatory strategies has added complexity to regulation setting. The waterfowl management community can address this by acquiring information about hunter values, behaviors, perceptions, and preferences and use these data to inform objective setting. Although gaps in our understanding of the ecological processes behind waterfowl populations undoubtedly will remain, the waterfowl community is even further behind in our understanding of the attitudes and behavior related to waterfowl conservation. Additional monitoring tools or programs will be needed to measure progress toward objectives for hunter participation and satisfaction (Johnson et al. 2015).

The focus for harvest regulations across the flyways primarily has involved mallards. As such, a key hurdle in developing regulatory alternatives or revising harvest strategies has involved consideration of stocks other than mallards. Innovative regulatory alternatives are needed to meet the multiple challenges of providing adequate hunting opportunity for abundant stocks, protecting less abundant species, and meeting diverse hunter preferences. However, the Central Flyway's hunter's choice experiment (2006-2009) has been the only large-scale experiment to occur since 1995 (Gammonley et al. 2010). Shrinking budgets and eroding support for monitoring and assessment, however, present upcoming challenges for AHM (Johnson et al. 2015). Thus, institutional change must involve thinking about harvest regulations in a culture of rigorous experimentation and adaptive management.

\section{Landscape Priorities}

The NAWMP was founded on the premise that waterfowl population goals would be achieved and sustained through the collective impacts of numerous, local-scale habitat conservation efforts. Landscapes vary in their importance to waterfowl populations, influenced by the types, amount, and quality of habitats occurring within them and how those habitats address limiting demographic rates (Smith et al. 1989, Mattsson et al. 2012). The need to focus conservation actions on regions and habitats most influential to waterfowl has been recognized since at least the mid-twentieth century (Kortright 1942, Linduska 1964). The 1986 NAWMP served as a milestone toward codifying this philosophy by identifying "waterfowl habitat areas of major concern in the United States and Canada" and stimulating establishment of the initial $6 \mathrm{JV}$ partnerships in regions overlapping these priority landscapes (U.S. Department of Interior and Environment Canada 1986:10).

The 2012 NAWMP reemphasized the importance of focusing resources on areas having the greatest effect on waterfowl populations, but it also acknowledged that habitat decisions can influence the recruitment and retention of supporters. Our understanding of individual motivations and behaviors among conservation supporters remains nascent (Cooper et al. 2015), yet it seems likely that the implications of habitat decisions on conservation supporters will vary among regions. In recognition of this, the 2012 NAWMP recommended the development of spatial models to identify priority landscapes where conservation resources should be directed to most effectively achieve its interrelated goals.

Waterfowl conservationists have made great strides in using geospatial models to prioritize landscapes for conservation action. The most notable examples are those developed to predict distributions of breeding ducks in the prairie pothole region under the premise that areas of high breeding duck density should be priority for protection (Reynolds et al. 2006, Doherty et al. 2015). Researchers extended these models to reflect land conversion risk and conservation (i.e., easement) costs, thus identifying areas of greatest conservation efficiency (Walker et al. 2013). Importantly, they effectively demonstrated the utility of geospatial models as frameworks for jointly considering (i.e., integrating) multiple objectives within a habitat decision context. Although heavily influenced by objectives for waterfowl productivity, these efforts provide a strong foundation for addressing a diverse suite of objectives and considering the tradeoffs among them when identifying priority landscapes.

Geospatial models and their resulting mapping products have become common tools for integrating ecological, economic, and other socially defined values (e.g., aesthetics, recreation) into landscape conservation plans. Socially defined values have been mapped most frequently based on input from stakeholders identifying areas perceived to satisfy selected social values (Alessa et al. 2007, Raymond et al. 2009). Where the provision of ecosystem services can be linked to landscape attributes, spatial variation in the ability of landscapes to provide these services can be quantitatively modeled from geospatial datasets (Nelson et al. 2009, Lesslie 2012). Multi-criteria decision analysis has been used to integrate spatial landscape priorities across ecological or socially defined values (i.e., objectives; Lesslie 2012), wherein these values may be weighted differently (i.e., multi-attribute theory; Keeney and Raiffa 1993) to produce a map reflecting areas of greatest composite value.

The combination of geospatial models and multi-criteria decision analysis is valuable because it provides a transparent process for assembling and merging stakeholder input with biophysical data (Nelson et al. 2009) and enables explicit examination of tradeoffs among objectives (Klein et al. 2009, Bryan et al. 2011). In some cases, models may reveal significant overlap in priority areas for achieving different objectives, thereby indicating minimal tradeoffs when selecting areas to invest conservation resources (Nelson et al. 2009). Yet other applications, depending on the objectives, weights, and geographic areas being modeled, may expose little overlap of important landscapes and, therefore, high degrees of tradeoff (Bryan et al. 2011). 
Lesslie (2012) offered a relevant example of geospatial modeling and multi-criteria analysis to identify priority landscapes for achieving multiple conservation objectives. In this example, a spatial decision support model identified priority areas for revegetation to achieve the joint objectives of enhancing habitat connectivity, restoring habitats for rare and threatened species, and sequestering carbon. A userfriendly, internet-based application was developed to allow conservation planners to build custom models of landscape priorities by combining spatial datasets, formulating relationships among them, and assigning weights to individual objectives (Lesslie 2012). The interactive nature of this application allowed stakeholders to view and evaluate the resulting tradeoffs in landscape priorities. We believe models and applications of this type would be useful for advancing conservation efforts on behalf of the interdependent NAWMP objectives.

Waterfowl ecologists have spent decades building an understanding of the relationships among conservation actions, landscape attributes, and their interactive effects on waterfowl demographics. A forthcoming challenge will be developing a similar understanding of relationships between habitat conservation actions at relevant scales and the variety of ecosystem services and supporter objectives upon which continued relevance of the NAWMP depends. For example, Yang et al. (2008) modeled the effects of wetland restoration on water quality and downstream discharges in a prairie watershed. Another example may involve providing greater access to hunting land through strategically located habitat restoration, potentially alleviating an impediment to hunter recruitment and retention (National Shooting Sports Foundation and Responsive Management 2011). Where it exists, empirical data will be vital for constructing relationships between landscape attributes and the contributions that conservation actions make toward enhancing ecosystem services and conservation support. Where empirical data are lacking, expert opinion initially will be a source for hypothesized relationships. In all cases, a commitment to the principles of adaptive management will be essential for testing and refining these hypotheses.

Revised NAWMP objectives at a continental scale (NAWMP Committee 2014; Table 1) likely will need to be translated to metrics and values relevant at regional scales to enable successful prioritization and implementation. Although continental-scale depictions of important landscapes are valuable for coarse-grained decisions and programs, they are likely inadequate for influencing conservation decisions having the greatest potential to affect NAWMP goals. Defining the appropriate scale of management problems is an essential feature of effective decision making. Most spatial decision support tools for targeting conservation have been established at regional scales, which reflects the geographic uniqueness of conservation decisions and the typical institutional scale of decision authorities (Reynolds et al. 2006, Lesslie 2012, Walker et al. 2013). From the outset, the NAWMP recognized regionally based partnerships as the most effective vehicle for planning and delivery of waterfowl habitat conservation.
Ultimately, identification of priority landscapes to achieve the goals of the 2012 NAWMP will require new approaches and clear articulation of objectives. Conservation planning will require stakeholder input to understand how individuals value waterfowl, waterfowl habitats, and related services and to understand the motivations for landowner participation in conservation programs (Knight and Cowling 2010). These considerations can be pursued as integral pieces of the decision problem and geospatial modeling process. Indeed, some JVs already are using social science methods at the scale of their conservation delivery to better understand and incorporate motivations of stakeholders in planning programs.

\section{Habitat Conservation Delivery}

The challenge of integration becomes more tangible at regional and local scales where the specific ecological and social factors affecting conservation decisions are more apparent and the potential solutions often are more evident. Here, the desire to increase societal relevance through integration may not necessarily involve tradeoffs. Greater attention to stakeholders' values and the use of social science methods are well suited to helping navigate perceived tradeoffs at this scale. Synergies may emerge that influence faster and more efficient (even creative) habitat delivery that ultimately benefit waterfowl but that may not be specifically targeted to achieve waterfowl objectives. Several examples follow.

Rainwater Basin Joint Venture (RWBJV).- - Habitat integration for hunters and waterfowl in the RWBJV involves providing public access to $>18,000$ ha of wetlands and associated uplands under public ownership (A. A. Bishop, USFWS, personal communication). To achieve these integrated objectives, strategic acquisition of roundouts will be needed to incorporate lands in private ownership that have a nexus with public wetlands. These areas will provide habitat for an estimated 4.3 million migrating waterfowl during the spring, $50 \%$ of which will occur on public lands (Rainwater Basin Joint Venture 2013). In addition, public use opportunities will be provided for 1.65 million Nebraska residents ( $90 \%$ of state's population) who live within 90 minutes of these wetlands. Use by waterfowl hunters, for example, is expected to approximate 115,000 hunter usedays. To acquire these parcels, the RWBJV will leverage a variety of funds, including grants from the Nebraska Environmental Trust, NAWCA, and sale of state waterfowl stamps.

Gulf Coast Joint Venture (GCJV). - The GCJV considers its priority focus to be developing and delivering science-based strategies for bird habitat conservation; however, the JV has sought opportunities to contribute to NAWMP user and supporter goals while maintaining its focus on habitat and birds (B. C. Wilson, USFWS, personal communication). Human dimensions considerations involve a suite of JV-scale objectives for hunters, viewers, and private landowners that are linked with overall NAWMP goals. The GCJV will consider hypothesized relationships related to supporters as NAWCA proposals are developed. The GCJV Board 
already has endorsed (2015) and implemented a process (2016) wherein these proposal criteria will be explicitly considered in semi-annual ranking of NAWCA proposals.

San Francisco Bay Joint Venture (SFBJV). - Encompassing a mostly urban geography, the SFBJV has recognized social values as integral to accomplishing both wetland and waterfowl goals (B. R. Huning, San Francisco Bay Joint Venture, personal communication). Outreach strategies have targeted specific audiences to gather information about preferences and benefits of upcoming projects. For example, prospective voters were surveyed about a regional ballot measure that was expected to generate approximately $\$ 50$ million annually for priority wetland habitat protection, restoration, enhancement, and management. Polling results, which showed that the majority of those surveyed valued birds and other wildlife, were used to develop content and messaging to promote support for the ballot initiative. Ultimately, the ballot initiative passed in June of 2016 with 70\% approval across the 9-county San Francisco Bay area. The SFBJV recognizes that public support is instrumental in all aspects of JV planning and implementation.

Playa Lakes Joint Venture (PLJV). - A scattershot approach of imprecise messages, informed by a 2006 survey of 1,800 concerned landowners, predominated messaging about recharge of the Ogallala Aquifer for more than a decade (M. F. Carter, Playa Lakes Joint Venture, personal communication). A focus group process conducted across the region in 2013 indicated that a greater number of landowners understood that playas recharge aquifers but lacked the knowledge they needed about the amount and rate of recharge to make decisions about whether to conserve or restore playas. In response, the PLJV held a summit with scientists and researchers who concluded that the amount and quality of recharge could support a small family farm, a rain-fed production system, or a grazing operation. They also recommended that water conservation plans for municipalities that depend on the aquifer include recharge through playas as a management action. A proposal related to municipal water supplies was successful in Clovis, New Mexico where city leaders partnered with the PLJV to submit their first NAWCA Small Grant. A Standard Grant, anticipated in 2017, would use city and county funds as match. The PLJV has determined that 58 cities surrounded by high-density playa complexes face water supply limitations (Alley et al. 1999). Implementation in and around Clovis would result in a $4 \%$ gain toward the PLJV's waterfowl objectives. Notably, implementation proceeded largely without perceived waterfowl tradeoffs even though the primary impetus has much less to do with waterfowl objectives and more so with habitat strategies focused primarily on other goals.

Integrating management for multiple objectives will be complex regardless of scale. No single landscape provides all annual life-cycle requirements for most waterfowl, harvest management within a flyway likely will not completely satisfy objectives for both waterfowl protection and hunter desires, and regional habitat management for ecological services might not directly target waterfowl abundance. Regardless, the waterfowl community has advanced these sorts of discussions during implementation of the 2012 NAWMP. Lacking simple solutions to complex problems, waterfowl managers must be purposeful in documenting assumptions, objectives, expected outcomes, evaluation, and developing a process for future NAWMP revisions.

\section{INCREASING ADAPTIVE CAPACITY}

Continued progress under the NAWMP will require, among other things, a continuing commitment to informed management decisions and a willingness to examine and possibly amend the processes and institutions presently in place that support waterfowl management. New elements of decision support undoubtedly will be needed. Among these are development and testing of new models and assumptions (Arnold et al. 2018), new or modified monitoring efforts to track progress in pursuing new objectives, resources for related assessments, and likely institutional and process adjustments to ensure that adaptation actually occurs in response to what is learned. The 2012 NAWMP recommendation for increasing adaptive capacity encompassed all of these. It was not simply a call for new funds, new staff, or new programming but rather for a thoughtful reconsideration of the most problematic uncertainties in waterfowl management, strategic use of existing resources, and if necessary, new incremental support (Roberts et al. 2018). The process of determining these needs is still at an early stage because the framework for integrated decision making is still evolving, but the commitment to adequate adaptive capacity will be vital if waterfowl conservation is to thrive with finite resources.

Adaptive Harvest Management has been the most durable specific application of adaptive management (Nichols et al. 2007, Johnson et al. 2015), operating in largely the same framework since 1995. Although several NAWMP JVs have made substantial commitments to adaptive habitat management with concomitant changes in conservation programs (Williams et al. 1999, Paulin et al. 2007, Prairie Habitat Joint Venture 2014), these have been more variable in scope, rigor, and duration. Most of these efforts to date are best described as single-loop learning (Fig. 3; Pahl-Wostl 2009), focused on assessing programs success, updating models, and adjusting management plans.

Only recently have some waterfowl managers begun the process of double or triple-loop learning (Fig. 3), which typically involve revisiting goals and objectives, re-assessing stakeholders, and perhaps restructuring institutions and processes. These are often referred to as reframing (doubleloop) and transforming (triple-loop) processes. Revision of NAWMP goals and objectives in 2012 and 2014 provides just the impetus needed to explore some of the transformative elements characteristic of triple-loop learning, centered on a quest for enhancing the relevance and sustainability of the waterfowl conservation enterprise.

Institutional changes of the magnitude envisioned in the NAWMP Revision are necessarily slow, messy processes, involving many actors with varying perspectives and agendas 
(Johnson et al. 2016, Roberts et al. 2018). There are 2 different perspectives of institutional transformation: one focuses on process, accountability, and planning for change; and the second focuses on an organic process of creativity, information sharing, and risk-taking (Kaner et al. 2014). Both views have something to offer, but the latter perspective suggests that more effort might be needed to understand and enable the process of change (Johnson et al. 2016). This involves recognizing that 1) small, rather than large, scales are the typical sources of innovation in management; 2) all decision making is heavily context dependent, and this dependency imposes limits on the integration of management programs; 3) change depends on the presence of intellectual diversity; 4) adaptive governance (i.e., institutional change) is fostered by the application of adaptive management; 5) tight feedback loops are essential for learning and for motivating change; and 6) the capacity for change depends on whether the resilience of the institution is sufficiently weak to allow for transformation. On the whole, it's worth remembering that transformation is not solely a product of positivistic planning but emerges at the boundary of order and chaos where learning and adaptation flourish (Waldrop 1992).

The NAWMP continues to evolve. Acknowledgement of the importance of social variability and change, evident throughout the 2012 NAWMP, represents a reality of wildlife conservation that often has not been explicitly integrated into conservation planning. Stakeholders, including those who make conservation decisions and those affected by them, must be more purposefully involved for the NAWMP and natural resource management in general to remain relevant into the future.

\section{ACKNOWLEDGMENTS}

We thank the organizers of the 7th North American Duck Symposium, notably C. K. Williams and S. E. Richman for the support in convening the 4 special sessions on the NAWMP. In addition to the presenters of each paper, we acknowledge their co-authors, G. Anderson, J. E. Austin, A. A. Bishop, G. S. Boomer, D. J. Case, R. G. Clark, P. Devers, J. H. Devries, J. A. Dubovsky, D. W. Howerter, A. H. Raedeke, J. Spaeth, M. Kilgore, H. Harshaw, M. Huang, B. R. Huning, J. R. Kelley Jr., B, J. Mattsson, E. E. Osnas, P. I. Padding, M. J. Petrie, and W. A. Phelps. We thank P. Devers and anonymous reviewers for suggested edits to early drafts. Funding for this project was provided in part by the U.S. Fish and Wildlife Service.

\section{LITERATURE CITED}

Alessa, L. N., A. A. Kliskey, and G. Brown. 2007. Social-ecological hotspots mapping: a spatial approach for identifying coupled social-ecological space. Landscape and Urban Planning 85:27-39.

Alley, W. M., T. E. Reilly, and O. L. Franke. 1999. Sustainability of ground-water resources. U.S. Geological Survey Circular 1186, Denver, Colorado, USA.

Anderson, M. G., R. T. Alisauskas, B. D. J. Batt, R. J. Blohm, K. F. Higgins, M. C. Perry, J. K. Ringelman, J. S. Sedinger, J. R. Serie, D. E. Sharp, D. L. Trauger, and C. K. Williams. 2018. The Migratory Bird Treaty and a century of waterfowl conservation. Journal of Wildlife Management 82: in press.
Anderson, M. G., F. D. Caswell, J. M. Eadie, J. T. Herbert, M. Huang, D. D. Humburg, F. A. Johnson, M. D. Koneff, S. E. Mott, T. D. Nudds, E. T. Reed, J. R. Ringelman, M. C. Runge, and B. C. Wilson. 2007. Report from the Joint Task Group for clarifying North American Waterfowl Management Plan population objectives and their use in harvest management. Department of the Interior, U.S. Fish and Wildlife Service and U.S. Geological Survey, Washington, D.C., USA.

Arlinghaus, R. 2006. On the apparently striking disconnect between motivation and satisfaction in recreational fishing: the case of catch orientation of German anglers. North American Journal of Fisheries Management 26:592-605.

Arnold, T. W., R. G. Clark, D. N. Koons, and M. Schaub. 2018. Integrated population models facilitate enhanced ecological understanding and improved management decisions. Journal of Wildlife Management 82: in review.

Blohm, R. J. 2006. Retrospective on waterfowl management over the last twenty years. Transactions of the North American Wildlife and Natural Resources Conference 71:179-196.

Bryan, B. A., C. M. Raymond, N. D. Crossman, and D. King. 2011. Comparing spatially explicit ecological and social values for natural areas to identify effective conservation strategies. Conservation Biology 25:172-181.

Case, D., and S. Sanders. 2008. The future of waterfowl management workshop: Framing future decisions for linking harvest, habitat and human dimensions. Report 10-9-08. https://nawmprevision.org/sites/ default/files/future_of_waterfowl_mgt_workshop_final report.pdf Accessed 25 Jan 2017.

Clark, C. W. 2005. Mathematical bioeconomics optimal management of renewable resources. John Wiley and Sons, Hoboken, New Jersey, USA.

Cooper, C., L. Larson, A. Dayer, R. Stedman, and D. Decker. 2015. Are wildlife recreationists conservationists? Linking hunting, birdwatching, and pro-environmental behavior. Journal of Wildlife Management 79:446-457.

Council to Advance Hunting and Shooting Sports. 2016. National hunting and shooting sports action plan: strategies for recruiting, retaining and reactivating hunting and shooting sports participants. Wildlife Management Institute and Council to Advance Hunting and Shooting Sports, Washington, D.C., USA. http://www.cahss.org/national-huntingshooting-sports-action-plan/. Accessed 25 January 2017.

Davidoff, P. and T. A. Reiner. 1962. A choice theory of planning. Journal of the American Institute of Planning 28:103-115.

Doherty, K. E., J. S. Evans, J. Walker, J. H. Devries, and D. W. Howerter. 2015. Building the foundation for international conservation planning for breeding ducks across the U.S. and Canadian border. PLoS ONE 10: e0116735. doi:10.1371/journal.pone.0116735

Driver, B. L. 1985. Specifying what is produced by management of wildlife by public agencies. Leisure Sciences 7:281-295.

Driver, B. L. 1996. Benefits-driven management of natural areas. Natural Areas Journal 16:94-99.

Driver, B. L., editor. 2008. Managing to optimize the beneficial outcomes of recreation. Venture. State College, Pennsylvania, USA.

Driver, B. L., and R. C. Knopf. 1976. Temporary escape: one product of sport fisheries management. Fisheries 1:21-29.

Fenichel, E. P., J. K. Abbott, and B. Huang. 2013b. Modelling angler behavior as a part of the management system: synthesizing a multidisciplinary literature. Fish and Fisheries 14:137-157.

Fenichel, E. P., B. Gentner, and R. Arlinghaus. 2013a. Normative considerations for recreational fishery management: a bioeconomic framework for linking positive science and normative fisheries policy. Fisheries Management and Ecology 20:223-233.

Freeman, D. M. 1992. Choice against choice: constructing a policyassessing sociology for social development. University of Colorado Press, Niwot, USA.

Fulton, D. C., M. J. Manfredo, and J. Lipscomb. 1996. Wildlife value orientations: a conceptual and measurement approach. Human Dimensions of Wildlife 1:24-47.

Fulton, D. C., D. Whittaker, and M. J. Manfredo. 2002. Planning and experience-based management. Pages 93-123 in M. J. Manfredo, editor. Wildlife viewing in North America: a management planning handbook. Oregon State University Press, Corvallis, USA.

Gammonley, J. H., M. P. Vrtiska, T. L. Shaffer, D. J. Witter, J. L. Hansen, M. A. Johnson, K. Kraai, F. NcNew, T. Mitchusson, D. Morrison, J. L. 
Richardson, L. Roberts, M. Szymanski, and S. Vaa. 2010. Evaluation of species-specific duck hunting regulations in the Central Flyway. Central Flyway Council, Denver, Colorado, USA.

Gregory, R. S., and R. L. Keeney. 2002. Making smarter environmental management decisions. Journal of the American Water Resources Association 38:1601-1612.

Hendee, J. C. 1974. A multiple satisfactions approach to game management. Wildlife Society Bulletin 2:104-113.

Herath, G., and T. Prato, editors. 2006. Using multi-criteria decision analysis in natural resource management. Ashgate Publishing Limited, Hampshire, United Kingdom.

Hilborn, R. 1987. Living with uncertainty in resource management. North American Journal of Fisheries Management 7:1-5.

Jahn, L. R., and C. Kabat. 1984. Waterfowl flyway councils: origin and role. Pages 373-386 in A. S. Hawkins, R. C. Hanson, H. K. Nelson, and H. M. Reeves, editors. Flyways: pioneering waterfowl management in North America. U.S. Government Printing Office, Washington, D.C., USA.

Johnson, F. A., G. S. Boomer, B. K. Williams, J. D. Nichols, and D. J. Case. 2015. Multilevel learning in the adaptive management of waterfowl harvests: 20 years and counting. Wildlife Society Bulletin 39:9-19.

Johnson, F. A., and D. J. Case. 2000. Adaptive regulation of waterfowl harvest: lessons learned and prospects for the future. Transactions of the North American Wildlife and Natural Resources Conference 65:94-108.

Johnson, F. A., D. J. Case, and D. D. Humburg. 2016. Learning and adaptation in waterfowl conservation: By chance or by design? Wildlife Society Bulletin 40:423-427.

Johnson, F. A., C. T. Moore, W. L. Kendall, J. A. Dubovsky, D. F. Caithamer, J. R. Kelley Jr., and B. K. Williams. 1997. Uncertainty and the management of mallard harvests. Journal of Wildlife Management 61:202-216.

Johnston, F. D., R. Arlinghaus, and U. Dieckmann. 2010. Diversity and complexity of angler behaviour drive socially optimal input and output regulations in a bioeconomic recreational-fisheries model. Canadian Journal of Fisheries and Aquatic Sciences 67:1507-1531.

Kaner, S., L. Lind, C. Toldi, S. Fisk, and D. Berger. 2014. Facilitator's guide to participatory decision-making. Jossey-Bass, San Francisco, California, USA.

Keeney, R. L. 2004. Making better decision makers. Decision Analysis 1:193-204.

Keeney, R. L., and H. Raiffa. 1993. Decisions with multiple objectives: preferences and value tradeoffs. Cambridge University Press, Cambridge, United Kingdom.

Klein, C., K. Wilson, M. Watts, J. Stein, S. Berry, J. Carwardine, M. S. Smith, B. Mackey, and H. Possingham. 2009. Incorporating ecological and evolutionary processes into continental-scale conservation planning. Ecological Applications 19:206-217.

Knight, A. T., and R. M. Cowling. 2010. Trading-off "knowing" versus "doing" for effective conservation planning. Pages 275-291 in N. LeaderWilliams, W. M. Adams, and R. J. Smith, editors. Trade-offs in conservation: deciding what to save. Wiley-Blackwell, Chichester, United Kingdom.

Kortright, F. H. 1942. The ducks, geese, and swans of North America. The American Wildlife Institute, Washington, D.C., USA.

Lesslie, R. 2012. Mapping our priorities-innovation in spatial decision support. Pages 156-163 in P. Figgis, J. A. Fitzsimons, and J. Irving, editors. Innovation for 21st century conservation. Australian Committee for IUCN Inc., Sydney, Australia.

Linduska, J. P., editor. 1964. Waterfowl tomorrow. United States Government Printing Office, Washington, D.C., USA.

Louviere, J. J, D. A. Hensher, and J. D. Swait. 2000. Stated choice methods: analysis and application. Cambridge University Press, Cambridge, United Kingdom.

Manfredo, M. J., editor. 2002. Wildlife viewing in North America: a management planning handbook. Oregon State University Press, Corvallis, USA.

Manfredo, M. J. 2008. Who cares about wildlife? Social science concepts for exploring human-wildlife relationships and conservation issues. Springer Press, New York, New York, USA.

Manfredo M. J., J. T. Bruskotter, T. L. Teel, D. C. Fulton, S. H. Schwartz, R. Arlinghaus, S. Oishi, A. K. Uskul, K. Redford, S. Kitayama, and L. Sullivan. 2016. Why social values cannot be changed for the sake of conservation. Conservation Biology 31:772-780.
Mattsson, B. J., M. C. Runge, J. H. Devries, G. S. Boomer, J. M. Eadie, D. A. Haukos, J. P. Fleskes, D. N. Koons, W. E. Thogmartin, and R. G. Clark. 2012. A modeling framework for integrated harvest and habitat management of North American waterfowl: case-study of northern pintail metapopulation dynamics. Ecological Modelling 225:146-158.

McFadden, D. 2001. Economic choices. American Economic Review 91:351-378

National Flyway Council and Wildlife Management Institute. 2006. National Duck Hunter Survey 2005. http://www.djcase.com/projects/ national-duck-hunter-survey. Accessed 25 January 2017.

National Shooting Sports Foundation and Responsive Management. 2011. Issues related to hunting access in the United States, final report. National Shooting Sports Foundation, Newtown, Connecticut, and Responsive Management, Harrisonburg, Virginia, USA.

Nelson, E., G. Mendoza, J. Regetz, S. Polasky, H. Tallis, D. R. Cameron, K. M. Chan, G. C. Daily, J. Goldstein, P. M. Kareiva, E. Lonsdorf, R. Naidoo, T. H. Ricketts, and M. R. Shaw. 2009. Modeling multiple ecosystem service, biodiversity conservation, commodity production, and tradeoffs at landscape scales. Frontiers in Ecology and the Environment 7:4-11.

Nichols, J. D., M. C. Runge, F. A. Johnson, and B. K. Williams. 2007. Adaptive harvest management of North American waterfowl populations: a brief history and future prospects. Journal of Ornithology 148(Suppl 2): S343-S349.

North American Waterfowl Management Plan Committee. 2014. Revised objectives: an addendum to the 2012 North American Waterfowl Management Plan. U.S. Fish and Wildlife Service, Washington, D.C., USA. http://nawmprevision.org/sites/default/files/NAWMP_Revised_ Objectives_North_American_Waterfowl_Management_Plan_Final_922-14.pdf Accessed 25 Jan 2017.

Pahl-Wostl, C. 2009. A conceptual framework for analyzing adaptive capacity and multi-level learning processes in resource governance regimes. Global Environmental Change-Human and Policy Dimensions 19:354-365.

Paulin, D., K. F. Abraham, M. G. Anderson, R. A. Bishop, R. G. Clark, L. Colpitts, J. M. Eadie, M. Petrie, E. T. Reed, F. C. Rohwer, A. Rojo, and M. W. Tome. 2007. North American Waterfowl Management Plan continental progress assessment. Final Report. http://nawmprevision.org/ sites/default/files/2007ContinentalAssessment.pdf. Accessed 2 February 2015.

Prairie Habitat Joint Venture. 2014. Prairie Habitat Joint Venture implementation plan 2013-2020: The Prairie Parklands. Report of the Prairie Habitat Joint Venture. Environnent Canada, Edmonton, Alberta. http://www.phjv.ca/pdf/PHJV\%20Implemenetation\%20Plan\% 20PRAIRIE\%20PARKLAND\%202013-2020\%20Final.pdf. Accessed 11 November 2016.

Rainwater Basin Joint Venture. 2013. The Rainwater Basin Joint Venture implementation plan. Rainwater Basin Joint Venture, Grand Island, Nebraska, USA

Raymond, C. M., B. A. Bryan, D. H. MacDonald, A. Cast, S. Strathearn, A. Grandgirard, and T. Kalivas. 2009. Mapping community values for natural capital and ecosystem services. Ecological Economics 68:1301-1315.

Reynolds, R. E., T. L. Shaffer, C. R. Loesch, and R. R. Cox Jr. 2006. The Farm Bill and duck production in the Prairie Pothole Region: increasing the benefits. Wildlife Society Bulletin 34:963-974.

Ringelman, J. K. 1997. Effects of regulations and duck abundance on duck hunter participation and satisfaction. Transactions of the North American Wildlife and Natural Resources Conference 62:361-376.

Roberts, A., J. M. Eadie, D. W. Howerter, F. A. Johnson, J. D. Nichols, M. C. Runge, M. P. Vrtiska, and B. K. Williams. 2018. Strengthening the links between waterfowl research and management. Journal of Wildlife Management 82:in press.

Rokeach, M. 1973. The nature of human values. Free Press, New York, New York, USA.

Runge, M. C., F. A. Johnson, M. G. Anderson, M. D. Koneff, E. T. Reed, and S. E. Mott. 2006. The need for coherence between waterfowl harvest and habitat management. Wildlife Society Bulletin 34:1231-1237.

Schwartz, S. H. 1992. Universals in the content and structure of values: theoretical advances and empirical tests in 20 countries. Advances in Experimental Social Psychology 25:1-65.

Schwartz, S. H. 2006. A theory of cultural value orientations: explication and applications. International Journal of Comparative Sociology 5:137-182. 
Smith, L. M., R. L. Pederson, and R. M. Kaminski. 1989. Habitat management for migrating and wintering waterfowl in North America. Texas Tech University Press, Lubbock, Texas, USA.

Teel, T. L., and M. J. Manfredo. 2009. Understanding the diversity of public interests in wildlife conservation. Conservation Biology 24:128-139.

Train, K. E. 2003. Discrete choice methods with simulation. Cambridge University Press, New York, New York, USA.

U.S. Department of the Interior and Environment Canada. 1986. North American Waterfowl Management Plan: a strategy for cooperation. U.S. Fish and Wildlife Service, Washington, D.C., USA. https://www.fws.gov/ birds/management/bird-management-plans/north-american-waterfowlmanagement-plan/plan-documents.php. Accessed 25 Jan 2017.

U.S. Department of the Interior, Environment Canada, and Environment and Natural Resources Mexico. 2012a. North American Waterfowl Management Plan: People Conserving Waterfowl and Wetlands. U.S. Department of the Interior, Washington, D.C., USA. https:// nawmprevision.org/. Accessed 26 Jan 2017.

U.S. Department of the Interior, Environment Canada, and Environment and Natural Resources Mexico. 2012b. North American Waterfowl Management Plan: Action plan. 2012. U.S. Department of the Interior, Washington, D.C., USA. https://nawmprevision.org/ Accessed 26 Jan 2017.

U.S. Fish and Wildlife Service [USFWS]. 2006. Strategic Habitat Conservation: A report from the National Ecological Assessment Team. U.S. Fish and Wildlife Service, Washington, D.C., USA. http://www.fws.gov/landscape-conservation/pdf/SHCReport.pdf. Accessed 25 January 2017.

Vaske, J. J., D. C. Fulton, and M. J. Manfredo. 2001. Human dimensions considerations in wildlife management planning. Pages 89-105 in D. J. Decker, T. L. Brown, and W. F. Siemer, editors. Human dimensions of wildlife management in North America. The Wildlife Society, Bethesda, Maryland, USA.

Vrtiska, M. P., J. H. Gammonley, L. W. Naylor, and A. H. Raedeke. 2013. Economic and conservation ramifications from the decline of waterfowl hunters. Wildlife Society Bulletin 37:380-388.
Waldrop, M. M. 1992. Complexity: the emerging science at the edge of order and chaos. Simon and Schuster, New York, New York, USA.

Walker, J., J. J. Rotella, C. R. Loesch, R. W. Renner, J. K. Ringelman, M. S. Lindberg, R. Dell, and K. E. Doherty. 2013. An integrated strategy for grassland easement acquisition in the Prairie Pothole Region, USA. Journal of Fish and Wildlife Management 4:267-279.

Walters, C. J. 1986. Adaptive management of renewable resources. McGraw Hill, New York, New York, USA.

Williams, B. K. 2011. Adaptive management of natural resources: framework and issues. Journal of Environmental Management 92:1346-1353.

Williams, B. K., and F. A. Johnson. 1995. Adaptive management and the regulation of waterfowl harvests. Wildlife Society Bulletin 23:430-436.

Williams, B. K., M. D. Koneff, and D. A. Smith. 1999. Evaluation of waterfowl conservation under the North American Waterfowl Management Plan. Journal of Wildlife Management 63:417-440.

Williams, B. K., J. D. Nichols, and M. Conroy. 2001. Analysis and management of animal population. Academic Press, New York, New York, USA.

Williams, B. K., R. C. Szaro, and C. D. Shapiro. 2007. Adaptive management: U.S. Department of the Interior technical guide. Adaptive Management Working Group, U.S. Department of the Interior, Washington, D.C., USA.

Wondolleck, J. M., and S. L. Yaffee. 2000. Making collaboration work: lessons from innovation in natural resources management. Island Press, Washington, D.C., USA.

Yang, W., X. Wang, S. Gabor, L. Boychuk, and P. Badiou. 2008. Water quantity and quality benefits from wetland conservation and restoration in the Broughton's Creek watershed. Ducks Unlimited Canada, Stonewall, Manitoba, Canada.

Associate Editor: Christopher Williams. 